\title{
Metode Kanguru Terhadap Fungsi Fisiologis Bayi Berat Lahir Rendah
}

\author{
Atik Purwandari ${ }^{1}$, Sandra G.J Tombokan ${ }^{2}$, Negin Lidya Clara Kombo ${ }^{3}$ \\ 1,2,3 Jurusan Kebidanan Politeknik Kesehatan Kemenkes Manado \\ Email : atikpurwandari75@yahoo.co.id;
}

Naskah Diterima : 02 Desember 2018 Disetujui : Februati 2019 Publikasi : Juni 2019

\begin{abstract}
ABSTRAK
Latar Belakang: Bayi Berat Lahir Rendah (BBLR) adalah bayi yang lahir dengan berat badan kurang dari 2.500 gram tanpa memperhatikan usia gestasi. Kelahiran dengan BBLR disebabkan oleh banyak faktor meliputi faktor janin, ibu dan plasenta. Pada BBLR yang harus dilakukan pemeriksaan fungsi organ tubuhnya, sebelum mencapai berat yang cukup bayi BBLR memerlukan perawatan intensif dalam inkubator, biaya perawatan yang cukup tinggi dan membutuhkan tenaga kesehatan yang berpengalaman. Sebagai solusi pemberian perawatan metode kanguru (PMK). Perawatan bayi baru lahir dengan meletakkan bayi dada ibu (kontak kulit) sehingga suhu tubuh bayi tetap hangat.

Tujuan : Penelitian ini bertujuan untuk mengetahui pengaruh PMK terhadap fungsi fisiologis BBLR di RSUP Prof Dr. R.D Kandou Manado.

Metode : Jenis penelitian ini adalah pre experimental design yang dilakukan terhadap 25 sampel yang ditentukan secara purposive sampling. Pengumpulan data diperoleh dari hasil observasi sebelum dan setelah dilakukan PMK.

Hasil : Analisa bivariat menunjukkan adanya pengaruh PMK terhadap fungsi fisiologis BBLR diantanya suhu badan sebelum diberikan PMK $=36,316$ setelah diberikan PMK nilai mean untuk suhu badan $=36,684$, nilai $\mathrm{t}=13,677(\mathrm{p}=0,000)$, denyut jantung sebelum diberikan PMK memperoleh nilai mean $=97,48$ setelah diberikan PMK nilai mean untuk denyut jantung $=121,440$, nilai $\mathrm{t}=17,078(\mathrm{p}=0,000)$, dan saturasi oksigen sebelum diberikan PMK memperoleh nilai mean $=$ 88,080 setelah diberikan PMK memperoleh nilai mean untuk saturasi oksigen $=94,320$, nilai $\mathrm{t}=$ $9,774(\mathrm{p}=0,000)$. Analisis data menggunakan uji t berpasangan.

Kesimpulan : Berdasarkan hasil penelitan yang didapat diharapkan PMK yang dilakukan di RSUP Prof Dr. R.D Kandou Manado, bisa dijadikan sebagai tindakan rutin yang dilakukan kepada BBLR bila kondsi bayi memungkinkan dilakukan PMK, dan sebaiknya memiliki rumah singgah bagi ibu yang memiliki bayi yang masih dirawat, agar lebih mudah mengunjungi bayinya.
\end{abstract}

\section{Kata kunci : Perawatan Metode Kangguru; Fungsi Fisiologis; Berat Badan bayi Lahir}

\section{PENDAHULUAN}

Salah satu indikator kesehatan suatu bangsa masih dilihat dari tinggi atau rendahnya angka kematian bayi (1) Menurut Kemnekes tahun 201, angka Kematian Bayi (AKB) merupakan salah satu indikator pembangunan kesehatan SDG's, salah satu tujuan SDG's adalah mengakhiri kematian yang dapat dicegah pada bayi baru lahir dan balita, dengan menurunkan Angka Kematian Neonatal

hingga 12 per $1.000 \mathrm{KH}$ dan Angka Kematian Balita 25 per $1.000 \mathrm{KH}$.

Angka Kematian Bayi (AKB) adalah jumlah kematian bayi dalam usia 28 hari pertama kehidupan per 1000 kelahiran hidup. Angka Kematian Bayi menurut WHO (World Health Organization) tahun 
2015 di negara ASEAN (Association of South East Asia Nations) seperti di Singapura 3 per 1000 kelahiran hidup, Malaysia 5,5 per 1000 kelahiran hidup, Thailand 17 per 1000 kelahiran hidup, Vietnam 18 per 1000 kelahiran hidup, dan Indonesia 27 per 1000 kelahiran hidup. Di Indonesia data dari kemneks tahun 2016 menunjukkan angka kematian bayi berangsur-angsur mengalami penerunan, pada tahun 2014 26,6 per 1000 kelahiran hidup, 201526 per 1000 kelahiran hidup, dan pada 2016 25,5 per 1000 kelahiran hidup. Namun demikian AKB di Indonesia masih termasuk tinggi dibandingkan angka kematian negara tetangga seperti di singapura dan Malaysia.

Penyebab utama kematian neonatal di Indonesia menurut SDKI tahun 2012 terbanyak yaitu BBLR (35\%), asfiksia $(33,6 \%)$, tetanus (31,4\%). Capaian penanganan neonatal dengan komplikasi mengalami penurunan dari tahun 2014 sebesar $59,68 \%$ menjadi $51,37 \%$ pada tahun 2015. Pada tahun 2015 capaian tertinggi diperoleh Provinsi Kepulauan Bangka Belitung dengan angka sebesar 90,01\% diikuti Jawa Tengah sebesar $89,23 \%$, dan Jawa Timur sebesar 82,91\%, Sulawesi utara sebesar 44,67\%. Tiga provinsi dengan capaian terendah ialah
Sulawesi Selatan (2,63\%), Papua $(5,19 \%)$, dan Maluku (8,86\%).

Sementara menurut data dari profil kesehatan Indonesia tahun 2016 menunjukkan bayi dengan berat lahir rendah (BBLR) merupakan salah satu faktor resiko yang mempunyai kontribusi terhadap kematian bayi. Dibandingkan dengan data Riskesdas tahun 2013 kejadian BBLR di Indonesia tertinggi ditemukan pada propinsi Sulawesi Tengah (16,8\%), Papua $(15,6 \%)$, Nusa Tenggara Timur (15,5\%), diikuti dengan propinsi lain seperti Gorontalo (13,2\%), Nusa Tenggara Barat (12,2\%), DIY (8,3\%), Sulawesi Utara (8,0\%). Berdasarkan survei awal di RSUP Prof. Dr. R. D Kandou Manado kasus bayi berat lahir rendah pada tahun 2016 sebesar sebesar 107 kasus (19,5\%), dan pada tahun 2017 sebesar 122 kasus $(22,3 \%)$ terlihat peningkatan antara tahun 2016 dan tahun 2017.

Berbagai upaya kesehatan dilakukan untuk mengendalikan $\mathrm{AKB}$, diantaranya dengan mengupayakan agar persalinan dapat dilakukan oleh tenaga kesehatan di fasilitas kesehatan serta menjamin tersedianya pelayanan kesehatan sesuai dengan standar kunjungan pada bayi baru lahir, dapat dilihat dari cakupan persalinan oleh tenaga kesehatan pada tahun 2013 sebanyak 90,88\%, tahun 2014 sebanyak 
88,68\%. Sedangkan untuk cakupan pelayanan neonatal pada tahun 2013 sebanyak 87,23\% tahun 2014 sebanyak 93,33\%, tahun 2015 sebanyak 77,31\%.

Bayi berat lahir rendah (BBLR) berisiko untuk mengalami hipotermi. Hal ini disebabkan karena tipisnya lemak subkutan pada bayi sehingga sangat mudah dipengaruhi oleh suhu lingkungan. Hipotermi merupakan penyebab kematian bayi yang cukup tinggi. Pada bayi BBLR yang harus dilakukan adalah pemeriksaan fungsi organ tubuhnya, sebelum mencapai berat yang cukup bayi BBLR memerlukan perawatan intensif dalam inkubator, biaya perawatan yang cukup tinggi dan membutuhkan tenaga kesehatan yang berpengalaman. Di RSUP Prof Dr.R.D Kandou sendiri memiliki. jumlah inkubator 18 unit, tidak sebanding dengan jumlah kasus BBLR yang membutuhkan perawatan inkubator pada bulan OktoberDesember sebanyak 38 bayi. Sebagai solusi pemberian perawatan metode kanguru (PMK), suhu optimal didapat lewat kontak langsung kulit ibu dengan kulit bayi (skin to skin contact). Suhu ibu merupakan sumber panas yang efisien dan murah, kontak erat ibu dan bayi membuat bayi merasa nyaman dan aman, serta meningkatkan perkembangan psikomotor bayi
Berdasarkan hasil penelitian oleh Deswita dkk terdapat pengaruh yang bermakna dari PMK terhadap respons fisiologis bayi prematur seperti peningkatan suhu tubuh ke arah suhu normal, peningkatan frekuensi denyut jantung kearah normal, peningkatan saturasi oksigen kearah normal, oleh karena itu, metode kanguru merupakan cara yang efektif, mudah, dan murah untuk perawatan bayi prematur (3) Pada penelitian yzng dilakukan oleh Wahyuni dan Parendrawati memberikan implikasi berupa informasi yang bermanfaat untuk mempromosikan posisi lateral dekubitus yang dapat memperbaiki kondisi psikologis ibu, neuromotor bayi, meningkatkan pelayanan konseling, dan memfasilitasi pembentukan kelompok pendukung PMK

(4)

\section{METODE}

Jenis penelitian yang digunakan adalah Pre experimental designs dengan rancangan onegroup pretest posttes. Penelitian ini dilakukan di RSUP Prof Dr R.D Kandou Manado pada bulan JanuariJuli 2018. Populasi dalam penelitian ini adalah semua bayi berat lahir rendah yang sedang menjalani perawatan di ruangan neonati pada bulan Juni- Juli 2018 sebanyak 33 bayi. Cara pengambilan sampel menggunakan teknik Purposive 
sampling. Variabel bebas dalam penelitian ini adalah Perawatan Metode Kanguru sedangkan variabel terikat adalah Fungsi Fisiologis Bayi Berat Lahir Rendah.
Instrument dalam penelitian ini adalah Lembar Observasi. Analisis yang digunakan adalah uji paried t test.

\section{HASIL}

\section{Analisis Univariat}

Table 1 Distribusi frekuensi umur, jenis persalinan, dan jenis kelamin bayi.

\begin{tabular}{lcc}
\hline Variable & Jumlah $(\mathrm{n}=25)$ & $\%$ \\
\hline Umur : & 8 & 32 \\
1 hari & 11 & 44 \\
2 hari & 6 & 24 \\
3 hari & & \\
Jenis Persalinan : & 14 & 56 \\
$\quad$ Spontan LBK & 11 & 44 \\
Sectio caesarea & & \\
Jenis kelamin : & 12 & 48 \\
Laki-laki & 13 & 52 \\
Perempuan & &
\end{tabular}

Tabel 1 menjelaskan bahwa

hasil pengolahan data untuk umur bayi paling banyak adalah bayi berumur 2 hari $(44 \%)$, jenis persalinan, paling banyak adalah persalinan Spontan letak Belakang Kepala (56\%) dan menurut jenis kelamin, paling banyak adalah bayi dengan jenis kelamin perempuan $(52 \%)$

Table 2 Distriobusi frekuensi Suhu Badan, Denyut Jantung dan Saturasi Oksigen Sebelum dan Setelah PMK

\begin{tabular}{lcc}
\hline & Sebelum PMK & Sesudah PMK \\
\hline Suhu badan : & 80 & 0 \\
$\quad$ Hipotermi & 20 & 100 \\
$\quad$ Normal & 76 & 0 \\
Frekuensi jantung : & 24 & 100 \\
$\quad$ Bradikardi & 88 & 0 \\
$\quad$ Normal & 12 & 100 \\
Frekuensi saturasi oksigen : & \multicolumn{2}{c}{ Perbedaan fungsi fisiologis bayi } \\
$\quad$ Kurang & berat lahir rendah (BBLR) sebelum dan \\
$\quad$ Normal & sesudah dilakukan perawatan metode \\
Table 2 menjelaskan suhu badan ada & kanguru (PMK) di RSUP Prof. Dr. R. D \\
han suhu badan, frekuensi jantung & Kandou Manado.
\end{tabular}


Tabel 3. Perbedaan Suhu badan bayi berat lahir rendah (BBLR) sebelum dan setelah dilakukan perawatan metode kanguru (PMK) di RSUP Prof. Dr. R. D Kandou Manado

\begin{tabular}{ccccc}
\hline Kelompok Bayi & Mean & SD & $\mathrm{t}$ & $p$ \\
\hline Suhu badan : & & & & \\
Sebelum PMK & 36,316 & 0,1625 & 13,677 & 0,001 \\
Setelah PMK & 36,684 & 0,1313 & & \\
Denyut jantung : & & & & \\
Sebelum PMK & 97,480 & 4,501 & 17,078 & 0,001 \\
Setelah PMK & 121,440 & 7,083 & & \\
Saturasi oksigen : & & & & \\
$\quad$ Sebelum PMK & 88,080 & 3,081 & 9,774 & 0,001 \\
Setelah PMK & 94,320 & 2,174 & & \\
\hline
\end{tabular}

Tabel 3 Menjelaskan bahwa, hasil analisis data memperoleh nilai mean untuk suhu badan sebelum diberikan PMK $=36,316, \mathrm{SD}=0,1625$ dan setelah diberikan PMK nilai mean untuk suhu badan $=36,684, \mathrm{SD}=0,1313$ nilai $\mathrm{t}=$ 13,677. Hasil uji statistik membuktikan bahwa terdapat perbedaan yang bermakna antara suhu badan bayi BBLR sebelum diberikan PMK dan suhu badan bayi setelah diberikan PMK, untuk denyut jantung sebelum diberikan PMK memperoleh nilai mean $=97,48, \mathrm{SD}=$ 4,5011 dan setelah diberikan PMK nilai mean untuk denyut jantung $=121,440$, SD $=7,0833$ nilai $\mathrm{t}=17,078$. Hasil uji statistik membuktikan bahwa terdapat perbedaan yang bermakna antara denyut jantung bayi BBLR sebelum diberikan PMK dengan denyut jantung bayi setelah diberikan PMK, semenstara saturasi oksigen sebelum diberikan PMK memperoleh nilai mean $=88,080, \mathrm{SD}=3,081$ dan setelah diberikan PMK memperoleh nilai mean untuk saturasi oksigen $=94,320, \mathrm{SD}=$ 2,174 nilai $\mathrm{t}=9,774$. Hasil uji statistik membuktikan bahwa terdapat perbedaan yang bermakna antara saturasi oksigen bayi BBLR sebelum diberikan PMK dengan staurasi oksigen bayi setelah diberikan PMK.

\section{PEMBAHASAN}

Analisis univariat meliputi umur ibu bayi, jenis kelamin, jenis persalinan serta tindakan sebelum dan sesudah PMK terhadap suhu badan, frekuensi jantung dan saturasi oksigen. Hasil dari penelitian ini menunjukkan umur bayi bervariasi antara 1 hari sampai dengan 3 hari, dengan umur seperti ini akan berisiko terhadap perubahan fisiologis dari bayi dengan berat lahir rendah.

Analisis bivariate menunjukkan hasil penelitian ini bahwa terdapat perbedaan yang terdapat perbedaan yang bermakna antara suhu badan bayi BBLR sebelum 
diberikan PMK dan suhu badan bayi setelah diberikan PMK,. Bayi premature cenderung memiliki suhu yang abnormal disebabkan oleh produksi panas yang buruk dan peningkatan kehilangan panas. Kegagalan untuk menghasilkan panas yang adekuat disebabkan tidak adanya jaringan adiposa coklat (yang mempunyai aktivitas metabolic yang tinggi). Kehilangan panas yang meningkat karena adanya permukaan tubuh yang realtif besar dan tidak adanya lemak subkutan, tidak adanya pengaturan panas bayi sebagian disebabkan oleh panas immature dari pusat pengatur panas, keadaan ini disebabkan oleh mekanisme keringat yang cacat. Pada minggu pertama dari kehidupan, bayi preterm memperlihatkan fluktuasi nyata dalam suhu tubuh dan hal ini berhubungan dengan fluktuasi suhu lingkungan. Ketidakdtabilan fungsi fisiologis BBLR dan sulitnya beradaptasi terhadap lingkungan yang berlebiahn menyebabkan bayi memiliki faktor resiko tinggi terkena penyakit komplikasi seperti asfiksia, bradikardi, penyakit paru kronis, hiperbilirubinemia, kejang, distress pernafasan ${ }^{(\mathbf{5})}$.

Hal ini sejalan dengan penelitian yang dilakukan oleh diketahui bahwa setelah diberikan metode kanguru berat badan bayi mengalami kenaikan, dimana berat badan bayi memiliki rata-rata yang lebih tinggi dibandingkan kelompok kontrol. Hal ini dikarenakan metode kanguru mampu: meningkatkan hubungan emosi ibu-anak, menstabilkan suhu tubuh, denyut jantung, dan pernafasan bayi, meningkatkan pertumbuhan dan berat badan bayi dengan lebihnbaik., mengurangi stress pada ibu dan bayi, mengurangi lama menangis pada bayi, memperbaiki keadaan emosi ibu dan bayi, meningkatkan produksi ASI, menurunkan resiko terinfeksi selama perawatan di rumah sakit, mempersingkat masa rawat di rumah sakit, dimana kondisi tersebut sangat mendukung peningatkan berat badan bayi BBLR secara optimal, yaitu adanya peningkatan produksi ASI dan suhu tubuh yang kondusif ${ }^{(3)(6)}$.

Berdasarkan hasil penelitian terdapat pengaruh yang bermakna dari perawatan metode kanguru terhadap respons fisiologis bayi prematur seperti peningkatan suhu tubuh yang semula hipotermia ke arah suhu normal. Jadi Perawatan Metode Kanguru dapat meningkatkan suhu tubuh bayi, dan mengurangi terjadinya hipotermia pada bayi prematur dan bayi yang lahir dengan proses caesar. Dengan mempertahankan suhu lingkungan yang hangat pada bayi prematur sangat dibutuhan untuk efisiensi 
metabolisme atau konservasi energi tubuh yang diukur melalui mengurangan kalori. Penurunan atau penghematan kalori diharapkan dapat memperbaiki perubahan fisiologis, dan mengakibatkan pertumbuhan yang lebih cepat pada bayi (7)

Berdasarkan hasil penelitian diketahui bahwa terdapat perbedaan yang bermakna antara denyut jantung bayi BBLR sebelum diberikan PMK dengan denyut jantung bayi setelah diberikan PMK, yang memperoleh nilai $p=0,000$. Hal ini sejalan dengan penelitian sebelumnya menyatakan bahwa adanya perbedaan peningkatan suhu tubuh bayi BBLR antara sebelum dan sesudah dilakukan perawatan metode kanguru, pada metode kanguru tidak terjadi proses kehilangan panas baik melalui radiasi,evaporasi, maupun konduksi sedangkan dengan inkubator masih dapat terjadi proses kehilangan panas melalui radiasi yang dapat mencapai > 50\% Metode Perawatan Metode Kanguru ini merupakan metode yang dilakukan pada BBLR secara kontak langsung antara kulit ibu dan bayi. Dimana bayi akan merasakan kehangatan ibunya dan detak jantung ibu. Kedekatan dan kontak secara langsung (8)(7)
Berdasarkan hasil penelitian diketahui terdapat perbedaan yang bermakna antara saturasi oksigen bayi BBLR sebelum diberikan PMK dengan staurasi oksigen bayi setelah diberikan PMK, yang memperoleh nilai $p=0,000$. Fungsi fisiologis bayi dilihat dari saturasi $\mathrm{O} 2$ diketahui bahwa rata-rata saturasi $\mathrm{O} 2$ BBLR mengalami perubahan ke arah normal yang semula semua bayi dalam kondisi saturasi O2 kurang. Dengan metode Perawatan Metode Kanguru dapat menjaga kestabilan saturasi oksigen. Perawatan Metode Kanguru secara bermakna mengurangi frekuensi nafas dan meningkatkan saturasi oksigen. Hal ini bisa disebabkan oleh posisi bayi yang tegak, sehingga dipengaruhi oleh gravitasi bumi dan berefek pada ventilasi dan perfusi respirasi. Melalui Perawatan Metode Kanguru rata-rata saturasi $\mathrm{O} 2$ darah mengalami peningkatan yang semula kurang pada BBLR dan terjadi peningkatan oksigen sebesar 9\% setelah dilakukan perawatan metode kanguru dimana bayi sudah nyaman beradaptasi sehingga dapat meminimalkan konsumsi oksigen jaringan ${ }^{(9)}$

\section{KESIMPULAN}

Ada pengaruh perawatan metode kanguru terhadap fungsi fisiologis bayi berat lahir rendah 


\section{SARAN}

Perawatan metode kanguru dapat direkomendasikan sebagai tindakan rutin yang dilakukan kepada bayi berat lahir rendah di RSUP Prof Dr. R.D Kandou Manado.

\section{DAFTAR PUSTAKA}

1. Maryunani. Inisisi Menyusui Dini, ASI Eklusif dan Manajemen Laktasi. Jakarta: EGC; 2012.

2. Walyani ES, Purwoastuti TE. Asuhan Kebidanan Persalinan Dan Bayi Baru Lahir. Yogyakarta: Pustaka Baru Press; 2015.

3. Deswita, Besral, Rustina Y. Pengaruh Perawatan Metode Kanguru terhadap Respons Fisiologis Bayi Prematur. Kesmas, J Kesehat Masy Nas. 2011;5(5):227-33.

4. Wahyuni S, Parendrawati DP. Pengalaman Ibu dalam Melakukan Perawatan Metode Kanguru. JKP. 2013;1(3):183-95.

5. Astuti D., Mutoharoh S, Priyanti R. Pengaruh Perawatan Metode Kanguru Dengan Peningkatan Berat Badan Bayi Baru Lahir Rendah (BBLR). J Involusi Kebidanan. 2015;5:65-78.

6. Syamsu AF. Pengaruh Perawatan Metode Kanguru Terhadap Fungsi Fisiologis Bayi Prematur Dan Kepercayaan Diri Ibu Dalam Merawat Bayi. J Keperawatan Soedirman (The Soedirman J Nursing). 2013;8(3):163-75.

7. Zakiah, Noor NBZ, Setiawati E. Efektifitas Peningkatan Suhu Tubuh Pada Perawatan Metode Kangguru Dengan Perawatan Inkubator Di Blud Rs H. Boejasin Pelaihari Tanah Laut Tahun 2013. J Skala Kesehat. 2014;5(1).

8. Perinasia. Perawatan Bayi Berat Lahir Rendah dengan Metode Kanguru. Jakarta: Petinasia; 2008.

9. Farida D, Yuliana AR. Pemberian Metode Kangaroo Mother Care (KMC) Terhadap Kestabilan Suhu Tubuh dan Berat Badan Bayi BBLR. JPK. 2017;4(2). 